\title{
ANTIBACTERIAL ACTIVITY OF VOLATILE OIL OF IXORA COCCINIEA AGAINST BURN ISOLATES
}

\section{O.N.Shanmugapriya and S.Priya*}

P.G and Research Department of Microbiology, S.T.E.T. Women's College, Mannargudi,

T.Nadu, India

P.G Department of Biotechnology, S.T.E.T. Women's College, Mannargudi, T.Nadu, India

Corresponding Author: piri_333@yahoo.co.in, +91 9787392903

\section{ABSTRACT}

Volatile oils are one of the groups of secondary metabolites produced by some plants. Their probable users against burn microbes have received little attention. Burn swabs obtained from ten burned patients at Government hospital, led to the isolation of bacteria using standard methods, the microorganisms were isolated. Then chloroform, methanol and aqueous extract of volatile of Ixora Cocciniea against S.aureus, E.coli, Pseudomonas aeruginosa, P.vulgaris and K.pnemoniae exhibited antibacterial were found efficacious respectively.

Key words: Burn; antibacterial; volatile oil; metabolites.

\section{Council for Innovative Research}

Peer Review Research Publishing System

Journal of Advances in Natural Sciences

Vol. 2, No. 2

editorjansonline@gmail.com

www.cirworld.com 


\section{INTRODUCTION}

One of the survey conducted by the WHO report that more than $80 \%$ of the world's population still depends upon the traditional medicine for various diseases (Priya et al., 2002). Essential or volatile oil of plants have been variously reported to have medicinal applications. Medicinally they are used in aroma therapy, as insect repellents, larvicidal and insecticidal agents (Aisien et al., 2004). Many bacteria have been implicated in different burn ailments and disease conditions. Quite a number of synthetic antibacterial agents are known to be of use in reducing the population of the nondesirable burn microbes although to varying degrees of success. There is need to explore natural herbs with probable antimicrobial potential against dangerous burn microbes (Colombo and Bosisio, 1996). The present study was aimed at examine the probable antibacterial effects volatile oil of Ixora Cocciniea could show against burn isolates.

\section{MATERIALS AND METHODS}

\section{Collection of plants and extraction of volatile oil}

Ixora Cocciniea leaves were collected from cultivated sources in village sides, Orathanadu, Tamilnadu. The volatile oil of plant was extracted by distillation method using Clevenger type apparatus for 4 hours (African Pharmacopoeia 1986) and the volatile oil was obtained.

\section{Isolation of burn isolates}

Burn swab were obtained at burnt unit of burnt patients from Government hospital, Thanjavur, Tamilnadu. Sterile swabs were used to collect the burn samples. Serial dilution of $10-5$ of $1 \mathrm{ml}$ of the mixture was introduced in to a sterile petridish using the pour plate method in to cool molten nutrient agar which had been fortified with $1 \%$ starch. The pour plate was incubated at $370 \mathrm{C}$ for 24 hours. Different bacterial strains obtained as typical colonies were sub-cultured and there after purified several times on fresh nutrient agar plates. The isolated pure strains were screened for the antibacterial activity.

\section{Assay of antibacterial activity}

Antibacterial activity was tested by the disc diffusion method (Okoli and Iroegbu, 2004). A $0.2 \mathrm{ml}$ of volume of the standard inoculums (106-107 CFU) of the test bacterial strain was spread on Muller Hinton Agar (MHA) with a sterile bent glass rod spreader and allowed to dry. Then, $6 \mathrm{~mm}$-diameter wells were bored using cork bores in the MHA. Plant extracts of volatile oil were introduced into each well and allowed to stand for 1 hour at room temperature to diffuse the plants extracts into medium before incubation at $370 \mathrm{C}$ for 24 hours. The incubation zone diameter was measured by antibiotic zone reader to nearest $\mathrm{mm}$.

\section{Determination of Minimum Inhibitory Concentration (MIC)}

The MIC was determined for the antibacterial most efficient extracts, using the cylinder agar diffusion method as described by (Fyhrquist et al., 2002).

\section{RESULT AND DISCUSSION}

From the burnt patients examined in this work, five different organisms were obtained. Based on the colonial appearance, morphological characteristics coupled with appropriate biochemical characteristics like catalase, coagulase, oxidase, citrate, indole and motility tests (Cheesborough, 1984), the five different bacterial isolates were identified as E.coli, Proteus vulgaris, K.pneumonia, Pseudomonas aeruginosa and Staphylococcus aureus.

The topical application of this plant at the burnt produced significant healing activity which may be due to antibacterial activity of the chemical constituents present in the crude extract. Delays in healing process directly promote the microbial infection. Although the report of the studied plants for the treatment of burn infections is available in literature, found contradictory and equivocal reports on screening of their extracts against pathogens. Similar result of extracts of A.nilotica was found as effective growth controller of E.coli and P.aeruginosa . Depending upon the polarity of solvent, extract yields were found increasing as polarity increased. More yields were found in water extracts of plant volatile oil followed by chloroform. Least yield was found in methanol extract (Table-1).

Antibacterial activity by disc diffusion method exhibit that the strong inhibition of growth of Staphylococcus aureus was observed in volatile oil of Ixora Cocciniea. Moderate type antibacterial activity was observed in P.vulgaris, $P$.aeruginosa and K.pneumonia. The least inhibition was determined at E.coli of volatile oil of plant extracts (Musmeci et al ., 2003).

Volatile oils constitute a group of plant secondary metabolites which can best be obtained (from the plant organs containing them) through hydro distillation. This method produces the volatile oils in their original form without being mixed with any other groups of secondary metabolites. The MIC values for the volatile oil of Ixora Cocciniea were shown in table2. Among the five burnt bacterial isolates, the MIC of volatile oil of Ixora Cocciniea observed at E.coli by the minimum zone of inhibition (Wongkham et al., 2001).

The results of present study indicate that plant extracts showing positive microbial activity provide the scientific base to include the traditional practices in modern system of medicines. They may, therefore, provide new leads in the development of new antimicrobial drugs for the therapy of diarrhea and other infectious diseases caused by E.coli, $S$.aureus or $P$.aeruginosa. It would be helpful in carrying out bioassay-oriented fractionation of the active extracts to isolate best fraction and/or pure compound having antibiotic activities against burnt pathogens (Steenkamp et al., 2004). 


\section{CONCLUSION}

The overall results provide the evidences that the volatile oil of the plant have potent antimicrobial effects against some of the burnt pathogens. The study concludes that the plants are a reserve of biologically active substances. Volatile oils can be a significant source of a great diversity of chemical species equipped with antimicrobial capacity, the oil Ixora Cocciniea can have application in therapy of the burn infectious diseases is like substituents of certain antibiotics or like complementary agents used in synergy with the synthesis substances.

\section{REFERENCES}

1. Priya K.S., Gnanamani A., Radhakrishnan N., Babu M., 2002. Healing potential of Datura alba on burn wounds in albino rats. J. Ethnopharmacol. 83: 193-199.

2. Aisien M.S.O., Imasuen A.A., Wagbatsoma V.A., and Ayinde B, A. 2004. Preliminary evaluation of the repellent activity of some plant essential oils against sinuiium damnosum the vector of human onchocerciasis. International Journal of Tropical Insect Science, 24 (2): 196-199.

3. Colomb R.N., and Bosisio S.L. 2002. Glossary of Indian medicinal plants. National Institute of Science Communication, CSIR, New Delhi, India.

4. African pharmacopoeia (1986). Vol. 2. 1st ed. OAU/STRC Publications.

5. Okoli A.S., Iroegbu C.U. 2004. Evaluation of extracts of Anthocleista djalonensis, Nauclea latifolia and Uvaria afzalii for activity against bacterial isolates from cases of non-gonococcal urethritis. J. Ethnopharmacol. 92: 135-144.

6. Fyhrquist P., Mwasumbi L., Haeggstrom C.A.,Vuorela P. 2002. Ethnobotanical and antimicrobial investigation on some species of Terminalia and Combretum (Combretaceae) growing in Tanzania. J . Ethnopharmacol. 79 :169-177.

7. Cheeseborough M. 1984. Biochemical testing of microorganism . In: Medical for tropical countries. Microbiol. Low price edition. Butterwoth-Heineman Ltd., Oxford, 11: P.479.

8. Musumeci R., Speciale A., Costanzo R., Annino A., Ragusa S., Rapisarda A., Pappalardo M.S., Lauk L. 2003. Berberis aenensis C. Presl. extracts: antimicrobial properties and interaction with ciprofloxacine. Antimicrob. Agent, 22: 48-53.

9. Steenkamp V,Mathivha E, Gouws MC, Rensburg CEJ 2004. Studies on antibacterial, antioxidant and fibroblast growth stimulation of wound healing remedies from south. Afr. J. Ethnopharmacol. 95: 353-357.

10. Wongkham S., Laupattarakasaem P., Pienthaweechai K., Areejitranusorn P., Techanitiswad T. 2001. Antimicrobial activity of streblus asper leaf extract . Phytother. Res. 15:119-121.

Table-1: Antibacterial activity of Ixora Cocciniea volatile oil against burn isolates by disc diffusion method

\begin{tabular}{|l|l|l|l|}
\hline \multirow{2}{*}{ Burn isolates } & \multicolumn{2}{l|}{ Zone of inhibition (mm diameter \pm SD) } \\
\cline { 2 - 4 } & Aqueous extract & Methanolic extract & Chloroform extract \\
\hline E.coli & & & $2.3 \pm 0.06$ \\
\hline P. aeruginosa & $3.7 \pm 0.06$ & $1.07 \pm 0.7$ & $4.28 \pm 0.18$ \\
\hline K.pneumonia & $5.5 \pm 0.15$ & $2.85 \pm 0.85$ & $6.25 \pm 0.18$ \\
\hline Proteus vulgaris & $7.5 \pm 0.41$ & $5.21 \pm 0.04$ & $3.42 \pm 0.85$ \\
\hline S. aureus & $4.64 \pm 0.39$ & $2.42 \pm 0.82$ & $7.35 \pm 0.16$ \\
\hline
\end{tabular}

Table-2: MIC of Volatile oil against burns isolates

\begin{tabular}{|l|l|l|l|}
\hline \multirow{2}{*}{ Burn isolates } & \multicolumn{2}{|c|}{ Zone of inhibition (mm diameter \pm SD) } \\
\cline { 2 - 4 } & Aqueous extract & Methanolic extract & Chloroform extract \\
\cline { 2 - 4 } & & & 10 \\
\hline E.coli & 08 & 11 & 15 \\
\hline P. aeruginosa & 14 & 16 & 12 \\
\hline K.pneumonia & 18 & 15 & 18 \\
\hline Proteus vulgaris & 12 & 20 & 11 \\
\hline S. aureus & 10 & 25 & \\
\hline
\end{tabular}

